\title{
0 mundo do trabalho e as organizações: abordagens discursivas de diferentes significados
}

Roseli Figaro

- Professora Doutora na Escola de Comunicações e Artes da USP, com pós-doutorado em Ergologia, na Universidade de Provence, França

- Autora de Relações de Comunicação no mundo do trabalho (2008); Comunicação e trabalho. Estudo de Recepção: 0 mundo do trabalho como mediação da comunicação (2001) e organizadora de Gestão da Comunicação. Mundo do trabalho, Educação, Terceiro Setor e Cooperativismo (2005)

- Coordenadora do Grupo de Pesquisa Comunicação e Trabalho, CNPq/ECA-USP

- figaro@uol.com.br 
Discutem-se o conceito de mundo do trabalho e o discurso como materialidade da organização. Faz-se a crítica ao uso da comunicação como ferramenta para a conquista de públicos, reduzindo-a à estratégia de marketing. Critica-se a simplificação que se costuma fazer do conceito de trabalho, desqualificando-o como mal necessário ao entendê-lo apenas como meio de aquisição de bens e capitais. Objetiva-se apresentar uma abordagem de comunicação e trabalho instigadora de questões relevantes para as pesquisas na área. Desenhamse elementos críticos de políticas de comunicação no mundo do trabalho.

PALAVRAS-CHAVE: COMUNICAÇÃO • MUNDO DO TRABALHO • DISCURSO • ORGANIZAÇÕES

Abstract

This article discusses the concept of the working world and of discourse as being the core of an organization. It criticizes the use of communication as a tool for conquering the public, reducing it to a marketing strategy. It also criticizes the simplification of the concept of work, disqualifying it as a necessary evil when seeing it as a means for acquiring goods and capital. This article aims to present a communication and working approach that will instigate relevant questions to the research area. It also introduces critical elements of the communication policies of the working world.

KEYWORDS: COMMUNICATION • WORKING WORLD • DISCOURSE • ORGANIZATION

Resumen

Se discute el concepto de mundo del trabajo y el discurso como materialidad de la organización. Se hace una crítica al uso de la comunicación como herramienta para la conquista de públicos, que la reduce a una mera estrategia del marketing. Se critica también la simplificación cotidiana del concepto de trabajo, que lo descalifica como un mal necesario, al entenderlo solamente como un medio de adquisición de bienes y capital. El objetivo es presentar un abordaje de la comunicación y el trabajo instigadora de preguntas relevantes para las investigaciones en el área y dibujar elementos críticos de las políticas de comunicación en el mundo del trabajo.

PALABRAS CLAVE: COMUNICACIÓN • MUNDO DEL TRABAJO • DISCURSO • ORGANIZACIONES 
0 esforço de definir e de delimitar leva ao risco da simplificação. Mas, muitas vezes, é esse o perigo que se tem de correr para tentar participar de uma discussão, no processo de produção de conhecimento. É esse o risco que se corre neste artigo ao discutirmos o mundo do trabalho e as organizações a partir do campo da comunicação. Espera-se contribuir com os estudos que se afiliam à desmistificação do discurso das organizações que se vêem como sistemas onipresentes e onipotentes, desejosas de simular a totalidade das vozes que circulam na sociedade.

\section{0 mundo do trabalho}

Mundo do trabalho é o conjunto de fatores que engloba e coloca em relação a atividade humana de trabalho, o meio ambiente em que se dá a atividade, as prescrições e as normas que regulam tais relações, os produtos delas advindos, os discursos que são intercambiados nesse processo, as técnicas e as tecnologias que facilitam e dão base para que a atividade humana de trabalho se desenvolva, as culturas, as identidades, as subjetividades e as relações de comunicação constituídas nesse processo dialético e dinâmico de atividade. Ou seja, é um mundo que passa a existir a partir das relações que nascem motivadas pela atividade humana de trabalho, e simultaneamente conformam e regulam tais atividades. É um microcosmo da sociedade, que embora tenha especificidade, é capaz de revelá-la.

A atividade de trabalho é aquela que permite ao sujeito criar algo em benefício de outro e de si mesmo, a partir de prescrições consolidadas no conhecimento instituído (leis, ciência, normas) e da criação/inovação do conhecimento investido (experiência pessoal). Desse encontro objetivo tem-se o trabalho e o produto resultado dele em duas instâncias: a atualização da prescrição/conhecimento instituído; a atualização das relações sociais (culturais, comunicacionais, políticas). O trabalho, para Schwartz (1994) e para Schwartz e Durrive (2003), é o processo invisível que se dá no embate (como dramáticas do uso de si por si mesmo e de si por outro) entre o prescrito e o realizado - que comporta o coletivo e a individualidade - na transformação de algo em algo.

O trabalho não desaparece no produto produzido, pois se renova na atividade humana. Faz o ser humano progredir no domínio de seu ser, predispondo-o como um ser criador. Mas o produto do trabalho incorpora um valor. O trabalho. Único valor capaz de criar e transformar o material e o imaterial e, nesse sentido, quando é privatizado na forma de mercadoria, retira da coletividade um bem que pertence a todos. Por isso, a atividade de trabalho não pode ser vista fora da história. No sistema capitalista, ela é determinada como mercadoria e as relações entre as pessoas são escalonadas e hierarquizadas por meio da especificidade das características e dos valores que cada atividade de trabalho adquire em relação ao poder hegemônico (GRAMSCI, 1977). Este sistema econômico pressupõe o trabalho remunerado e o trabalho não-remunerado 
(apropriado como parte do capital, conforme Marx (1993), regulados pelo emprego e os diferentes vínculos contratuais entre os que se oferecem para o trabalho no mercado de trabalho.

O mundo do trabalho é uma categoria ampla, difusa e complexa, característica e fundamento da sociedade, pois lugar privilegiado que abriga grande parte da atividade humana. Ele é uma categorização ampla, porque possibilita congregar conceitos como trabalho, relações de trabalho, vínculo empregatício, mercado de trabalho, salário, tecnologia, troca, lucro, capital, organizações, controle, poder, sociabilidades, cultura, relações de comunicação.

No mundo do trabalho encontram-se os conflitos centrais que estruturam e regulam o sistema sócio-econômico e político (MARX, 1993). No mundo do trabalho são criadas e transformadas as formas e os temas presentes em outras esferas institucionais tais como a família, a escola, os meios de comunicação etc.

A partir do mundo do trabalho constituem-se várias institucionalidades: a organização empresarial, a organização sindical, órgãos do Estado que fiscalizam os direitos do trabalho e no trabalho, a legislação fiscal, sanitária, de saúde, de formação e de escolarização.

As relações de comunicação no mundo do trabalho pressupõem a circulação de discursos, enunciados por diferentes sujeitos e institucionalidades que o compõem. Enunciam-se e circulam discursos, sobretudo, de vários pontos de vista sobre o trabalho e sobre a regulação dele. Esses discursos revelam as ideologias dos setores e classes sociais ali presentes. O mundo do trabalho é tencionado por forças sociais (cujos discursos disputam a hegemonia) representativas das classes sociais ${ }^{1}$.

Se o mundo do trabalho forma-se da atividade de trabalho - como lugar do encontro e do confronto dos diferentes e das diferenças - ele também influencia as culturas relativas às especificidades das relações ali constituídas; sobretudo atua nas relações de comunicação que são hierarquizadas a partir das lógicas a ele inerentes.

É essa, portanto, a definição de mundo do trabalho a partir da qual se irá desenvolver a concepção de organização.

1 Na contemporaneidade, o debate sobre o problema da conceituação das classes que se opõem no sistema capitalista vem sendo escamoteado. Trata-se, a nosso ver, de integridade intelectual denunciar 0 aprofundamento das contradições entre as classes e definir, adotando a categorização de Antunes, 0 termo de classe-que-vive-do-trabalho para nos situarmos nessa discussão: "Nossa tese central é a de que, se a classe trabalhadora não é idêntica àquela existente em meados do século passado, ela também não está em vias de desaparição, nem ontologicamente perdeu seu sentido estruturante. (...) Devemos indicar, desde logo, que a classe trabalhadora hoje compreende a totalidade dos assalariados, homens e mulheres que vivem da venda da sua força de trabalho - classe-que-vive-do-trabalho, conforme nossa denominação (...) - e que são despossuídos dos meios de produção." (ANTUNES; ALVES, 2004, p. 336). 


\section{A organização}

A organização é uma instituição cartorial, legal, formada com objetivos bem definidos e regulados estatutariamente, dirigida por órgãos hierárquicos ocupados por determinação de posse, de representação política do Estado, ou por delegação. Funda-se a partir de um discurso. Tem uma fala sobre si e de si mesma, que lhe dá identidade, finalidade, atribuição, representação social e política. Tem uma marca. Tem um público. Sua finalidade é abarcar, por meio de sua institucionalidade e de seu discurso, a diversidade de atividades, atributos, vozes, finalidades, interesses que compreendem um grupo social ou o conjunto da sociedade. A organização é específica, tem um discurso, aquele que a fundamenta.

As organizações representativas dos direitos do trabalhador, seja uma entidade sindical, seja um órgão governamental, ou uma organização não-governamental, têm objetivos claros que as institui. Elas atuam de acordo com o programa que estabeleceram no sentido de reiterar, divulgar, fiscalizar e garantir o cumprimento das normas (leis) que regulam as relações de trabalho numa sociedade democrática; ou podem atuar no sentido de questionar e ampliar tais normas, incorporando, ao espectro delas, direitos ainda não reconhecidos como tais. Ou ainda, organizações de novo tipo, capazes de almejar garantir direitos, sobretudo aqueles que estão ligados à atividade de trabalho, ou seja, capazes de dimensionar numa mesma escala realização, produção, qualidade de vida, saúde, realização profissional ${ }^{2}$.

A organização empresarial fundamenta-se pela finalidade de organizar a produção de algo e/ ou de um serviço para torná-lo mercadoria. Identifica-se por meio de normas estabelecidas por um corpo diretivo, cujo objetivo é garantir o usufruto do bem que dá nome à organização. Há uma direção que nomeia tudo o que deve ser nomeado, regulando as relações hierárquicas e de poder. A finalidade dela, em última instância, não é o trabalho, não é a produção de um produto e/ ou serviço, mas sim a garantia de condições de apropriação dos valores da produção para que possa continuar existindo como institucionalidade que regula, normaliza, apropria-se e vende os bens e serviços produzidos. A organização empresarial é uma das organizações que se institui a partir do mundo do trabalho. Ela almeja abarcar a totalidade do que é o complexo mundo do trabalho, mas ela só pode simular ter controle dessa totalidade, pois tal controle é disputado por diversas organizações.

Os objetivos e o conjunto normativo que regulam a organização empresarial são unidirecionais. Foram estabelecidos por um núcleo dirigente, cuja principal missão é fazer deles (objetivos e normas) o discurso de identidade de toda a organização. Ele é sistêmico. A finalidade estabelecida pela organização não

2 Talvez o exemplo mais próximo a que se conseguiu chegar desse tipo de organização foram as comissões de fábrica, ou comissões de empresa, formadas por coletivos de trabalhadores eleitos. 
converge necessariamente para a finalidade do mundo do trabalho, visto que a primeira tem por finalidade perpetuar-se como particularidade e o mundo do trabalho tem como finalidade as condições de realização da atividade humana. Assim, no mundo do trabalho, para a plena realização da atividade, os sujeitos (corpo-si, para Schwartz (2003)) estão em relação solidária e comunicacional entre si. Estabelecem redes, laços pertinentes à realização da atividade. Laços tênues, sutis, imperceptíveis, muitas vezes, momentâneos, que se fazem e se desmancham de acordo com a pertinência e a necessidade da atividade. $\mathrm{O}$ mundo do trabalho é processo.

A organização almeja controlar tais redes de relações entre sujeitos. Ela vê a atividade como tarefa. Limitada, com começo, meio e fim. Mas a atividade é contínua, movimento próprio do sujeito em relação com seu meio. Para a organização empresarial o trabalho é apenas um problema a ser resolvido, um mal necessário, uma forma de aquisição de bens e capitais. E a comunicação na organização é vista como uma ferramenta para o controle e a conquista de públicos, para a construção de valores de marca, instrumento de consolidação de estratégias de marketing e de implantação de políticas de mudança cultural.

\section{Comunicação e trabalho a partir de um outro ponto de vista}

Ponto de vista que procura chamar a atenção para o mundo do trabalho, à medida que ele é mais amplo do que a organização. Por ele circulam diferentes discursos, oriundos de sujeitos e grupos sociais diversificados. As relações de comunicação no mundo do trabalho revelam a complexidade de nossa sociedade, revelam a cultura real (aquela que se constrói dos laços cotidianos entre as pessoas oriundas de diferentes grupos sociais, com formação diferenciada e exercendo atividades diversas) dos homens e mulheres em atividade de trabalho, os valores e as ideologias, bem como os conflitos ali existentes. Nele há vozes que não existem para a organização, não são reconhecidas ou não deveriam ter voz: as vozes dos trabalhadores.

Numa democracia de fato, as vozes presentes no mundo do trabalho ganham visibilidade e passam a reivindicar reconhecimento nas organizações. A organização empresarial não pode pretender falar por todas as vozes do mundo do trabalho. Ela não deve temer os diferentes discursos do mundo do trabalho. A atividade de trabalho precisa de liberdade para desenvolver-se. Cada vez mais a organização empresarial deveria preocupar-se em se afastar da pretensão de ser a detentora dos conhecimentos que estão circulando no mundo do trabalho, principalmente na atualidade, com todos os recursos existentes em termos de tecnologias da informação e da comunicação. Ela deve ser uma facilitadora. Sua missão cada vez mais é a de se tornar uma enunciadora de discursos normalizadores, como é de sua natureza no sistema econômico em que vivemos, mas cuja regularidade deve ser sensível à dinâmica e complexidade do mundo do trabalho. A comunicação, nesse sentido, não deve ser compreendida ape- 
nas como consenso, ela expõe conflitos, os quais são inteligíveis e explicáveis a partir das contradições inerentes à realidade social. Os discursos do mundo do trabalho não podem ser entendidos como ruído, problema, restrição. Por exemplo, é comum a organização empresarial desejar impedir a circulação de discursos não autorizados, denominados de conversas de corredor, rádio peão, corredor press etc., impondo a comunicação interna ou a comunicação organizacional. Esforço em vão e prejudicial à própria organização.

A comunicação é inerente à atividade humana de trabalho. São faces intrínsecas. Com essa afirmação confronta-se certo idealismo que desvincula a comunicação da atividade de trabalho. Até mesmo na história do desenvolvimento do corpo humano há marcas de que o surgimento de um tipo de comunicação se deu simultaneamente à atividade humana para a transformação do meio em prol de sua existência. A comunicação é uma conquista da espécie humana, efetivada pela condição do homem de sobrepor-se, por meio de sua atividade de trabalho, às condições da natureza.

A linguagem humana está ligada, desde a origem, à atividade produtiva, à "comunicação material dos homens" (LEONTIEV, 1976). Ou seja, a atividade para a sobrevivência, no enfrentamento das "infidelidades do meio", requer a comunicação entre os seres para que haja cooperação e, por conseguinte, superação das dificuldades. Dessa forma, a linguagem não é um meio de comunicação entre os homens, ela é constitutiva do homem e uma forma da consciência e do pensamento humanos. Ela acompanha, comenta, projeta a atividade de trabalho e, como afirma Bakthin (1988), é uma arena das lutas sociais. Ela reflete e refrata as menores mudanças sociais. A linguagem tem na palavra a síntese da arena das lutas sociais, porque se forja na dialética entre o estabelecido e o vir a ser. A palavra é sensível à mais ínfima mudança social porque é parte da atividade humana de trabalho. E é a atividade de comunicação e trabalho o material objetivo, com o qual se fabrica a realidade humana.

\section{Comunicação e linguagem como simulacros}

As transformações ocorridas no mundo do trabalho, no que diz respeito à organização da produção e a presença de novas tecnologias, a partir dos anos de 1990, no Brasil, e, desde os anos de 1980, nos Estados Unidos e nas principais economias da Europa, introduziram um novo paradigma baseado na produção flexível, na polivalência do trabalhador, na intensificação do ritmo de trabalho, na horizontalidade da produção e na autovigilância. A comunicação passa a ser entendida como uma ferramenta de persuasão e controle em favor da organização, acionada já na base do processo produtivo. Sinais luminosos, sonoros, palavras-chave entram no mundo do trabalho de forma planejada e instrumental.

Há o que se denomina aqui de "virada discursiva" das organizações, com o objetivo de implementar o arcabouço ideológico funcional da reestruturação 
produtiva e da flexibilização nos processos de racionalização e precarização do trabalho. Passa a circular na organização empresarial um conjunto de vocábulos oriundos de outras plataformas discursivas: tais como os da religião e os da publicidade. Vocábulos re-significados e impostos pelas organizações para tentar impedir o avanço de relações, de fato, mais democráticas entre a organização e o mundo do trabalho. Por exemplo, é muito comum o uso de vocabulário esvaziado de seu significado primeiro, palavras como colaborador, associação, equipe, missão, inovação, aprendizado, peregrinação, coleta, diálogo, participação que foram deslocadas para o ambiente das organizações empresariais com o intuito de simular o que não se realiza. A organização empresarial tem a pretensão de abarcar todos os discursos e de nomeá-los, criando um campo semântico simulador de relações de comunicação e de atividade de trabalho que de fato não existem. É uma estratégia discursiva planejada em grandes conglomerados organizacionais, instituições como a Organização de Cooperação e Desenvolvimento Econômico (OCDE); Fundo Monetário internacional (FMI); Organização Mundial do Comércio $(\mathrm{OMC})^{3}$ e disseminada mundo afora. Baseiam-se em concepções deterministas que tratam a comunicação como fluxo de informação e a linguagem verbal como palavra etiqueta que, ao nomear, impõe um e único sentido. Ignoram que a linguagem verbal como arena das lutas sociais, materializa, revela e esconde o que vai pela sociedade. É a realidade da atividade humana que organiza a expressão humana (SCHAFF, 1976).

As organizações ao construírem simulacros linguísticos operam a comunicação como uma ferramenta para a persuasão e o controle. Pretende-se monossêmica e ao assim procederem, revelam-se como verdadeiramente são: espaço de simulacro. Sempre como um discurso que omite um outro: aquele que está escondido, impedido de aparecer, aquele que revela os reais interesses da organização. Daí a política de comunicação ser simulação do que se passa nesse encontro entre a institucionalidade da organização empresarial e o mundo do trabalho.

As estratégias de aparente igualdade de interesses entre organização e mundo do trabalho revelam-se com escolhas que configuram "valores" mensuráveis monetariamente, cuja lógica vai de encontro (contra) aos valores não-mensuráveis, ou seja, aqueles valores da economia do corpo e da atenção, da saúde e da qualidade de vida, da eficácia do bem produzido e do valor do saber fazer profissional de cada sujeito, pertinentes ao mundo do trabalho.

Estudar o mundo do trabalho e a atividade de trabalho por meio da linguagem e da comunicação dos sujeitos (corpo-si) é a maneira mais eficiente de se aproximar da realidade do trabalho, dos desafios, dos conflitos que permeiam o ambiente de constante confronto entre as normas da organização e aquelas advindas do mundo do trabalho: as dificuldades em gerir as impertinências das condições de trabalho e de como tentar superá-las.

3 Estudo muito relevante para entender a influência do discurso dessas organizações nos países e nas empresas é o de Alves (2008). 
Quando se fala do discurso de máscara ressalta-se como a retórica pode servir à elaboração de um discurso que tenha coerência e coesão internas, mas que, muitas vezes, não condiz com o que a experiência das pessoas registra. A simulação do discurso democrático e participativo dentro das organizações empresariais perde em sentido porque não condiz com o aprendizado que a atividade de trabalho revela. Não há política de comunicação que possa dar suporte a discursos que vão à contramão da experiência adquirida na atividade de trabalho e na atividade de linguagem no trabalho (LACOSTE, 2000).

As relações de comunicação que se dão no mundo do trabalho demonstram a ineficácia dos discursos oficiais, representativos da norma e da hierarquia institucional. Ineficazes quando se pretendem os únicos a poderem circular no mundo do trabalho. Quando desconsideram que o processo de comunicação é criativo, pois pressupõe o sujeito (corpo-si). E este corpo-si em atividade de trabalho é pleno de história e experiência; esforça-se a todo o tempo para transformar o lugar de trabalho em seu lugar de trabalho, com seu círculo de relações, suas fontes (recursos e informações) de apoio.

\section{Desafios para estudos posteriores}

O estudo da comunicação no mundo do trabalho permite entender como se dá a resolução de problemas, e a partir de que valores as pessoas fazem suas escolhas; como se constituem os coletivos de trabalho que estão fora do enquadramento do organograma da empresa; como se constituem as redes de ajuda e solidariedade na resolução de problemas e tarefas. E ainda compreender como o mundo do trabalho transborda de seu meio e abarca outros espaços sociais, tais como a casa, o bairro, a mídia etc.

Formula-se, a partir do exposto, a proposta de se estudar as relações de comunicação no mundo do trabalho, tendo como base conceitual o binômio comunicação e trabalho. Pois a dimensão de comunicação e trabalho como atividade humana singular, tomada como resultado de um processo dialético na ontogênese e na filogênese da história, requer que o pesquisador coloque-se diante da realidade a conhecer de uma maneira a deixar transparecer as contradições. Possibilita, também, esclarecer dois eixos ou programas de pesquisa: a) com o objetivo de melhor conhecer a atividade de trabalho, portanto, o mundo do trabalho; e b) melhor entender as relações de comunicação, o processo de comunicação, os sujeitos (corpo-si) da comunicação.

Esses eixos de pesquisa podem ser organizados, colocando-se em prática a observação e a confrontação da comunicação a partir do que Schwartz e Durrive (2003) denominaram de Dispositivo Dinâmico em Três Polos. Ao ser aplicado às relações de comunicação no mundo do trabalho pode ser identificado como: eixo $A$ - normas, prescrições e discursos da organização; eixo $B$-saber investido, cultura real dos sujeitos (corpo-si) que estão em atividade de trabalho; e eixo $C$ 
- questionamento de como fazer melhor tendo como princípio o benefício da vida, da saúde física, mental e emocional, e do viver bem em conjunto.

\section{Quadro 1}

\section{Dispositivo dinâmico em três pólos}

\section{Eixo A}

Saberes e valores construídos no universo científico,normas, prescrições da organização

\section{Eixo B}

Saberes e valores da experiência, adquiridos na atividade, cultura real dos sujeitos.

\section{Eixo C - Pólo do questionamento}

Como fazer melhor em benefício da vida, da saúde física, mental e emocional, e do viver bem em conjunto
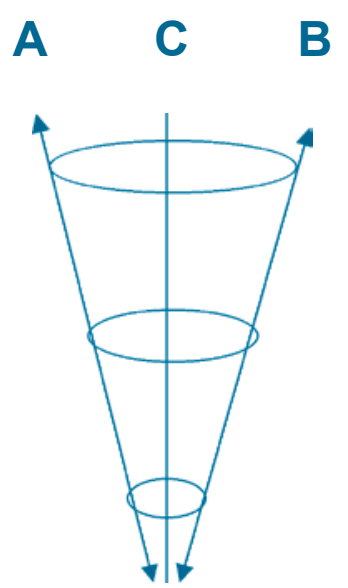

O eixo do questionamento é o fundamento do Dispositivo Dinâmico em Três Polos, porque permite confrontar a norma e a experiência pela atividade de trabalho, revelando os conflitos e as contradições sociais e, principalmente, a potencialidade de transformação dos sujeitos (corpo-si). Essa proposta permite ainda articular a dialética do micro ao macro-social. Ela ajuda a visualizar o papel que os responsáveis pela comunicação nas organizações podem desempenhar ao tomarem para si a responsabilidade de aplicar esse Dispositivo. A construção de um saber que leve em consideração a atividade humana - a atividade de trabalho - permite reformular os saberes constituídos e renoválos por meio do questionamento que tem por princípio valorizar e priorizar o polo da atividade como fonte de possibilidades. 


\section{Conclusão}

O mundo do trabalho não é sinônimo de organização empresarial. O mundo do trabalho é o conjunto de fatores que compreende atividade de trabalho, meio ambiente, conhecimentos instituídos e conhecimentos investidos, culturas e processos comunicacionais. A organização empresarial é uma das diversas institucionalidades presentes no mundo do trabalho. Ela é instituição legal, regulada por um conjunto de objetivos, dirigida por órgãos hierárquicos estabelecidos pelo critério de propriedade, ou por delegação política de Estado. Tem um discurso hegemônico.

Dessa forma, circulam pelo mundo do trabalho discursos plurais, oriundos de sujeitos e grupos e classes sociais diversos. Eles expressam a complexidade do mundo do trabalho e das disputas por hegemonia (GRAMSCI, 1976) de valores e de ideologias (BAKHTIN, 1988). Por ele passam os principais temas em conflito na sociedade.

Na sociedade democrática, a organização não deve pretender falar por todas as vozes que circulam no mundo do trabalho. A atividade de trabalho precisa de liberdade para se desenvolver. O estudo da comunicação no mundo do trabalho propicia entender a resolução de problemas e como os sujeitos mobilizam valores para fazer suas escolhas, como as culturas do trabalho constroem laços de solidariedade inerentes à atividade tão necessários para a vida em comunidade.

\section{Referências}

ALVES, Luiz Roberto. Trabalho, Cultura e Bem-comum (Leitura crítica internacional). São Paulo: Fapesp/AnnaBlume, 2008. ANTUNES, Ricardo. Os sentidos do trabalho. São Paulo: Boitempo, 2000.

ANTUNES, Ricardo, ALVES, Giovanni. As mutações do trabalho na era da mundialização do capital. Educação e Sociedade, v. 25, n. 87. Campinas, 2004, p, 335-351.

BACCEGA, Maria A. Palavra e discurso. História e literatura. São Paulo: Ática, 1995. . Comunicação e linguagem. Discursos e ciência. São Paulo: Moderna, 1998.

BAKHTIN, Mikhail. Marxismo e filosofia da linguagem. São Paulo: Hucitec, 1988. A estética da criação verbal. São Paulo: Martins Fontes, 1992.

FIGARO, Roseli A. Comunicação e trabalho. Estudo de recepção: o mundo do trabalho como mediação da comunicação. São Paulo: Anita Garibaldi/Fapesp, 2001.

Relações de comunicação no mundo do trabalho. São Paulo: AnnaBlume, 2008.

Atividade de Comunicação e de trabalho. Revista Trabalho, Educação, Saúde. Fiocruz. Rio de Janeiro, v. 6, n. 1, 2008. GRAMSCl, Antônio. Escritos políticos. Lisboa: [s.n.], 1977.

LACOSTE, Michele. Le langage et la struturation des collectifs. In: BENCHEKROUN, T. H.; WEIL-FASSINA, A. Le travail collectif. Perspectives actuelles en ergonomie. Toulouse: Octarès, 2000. p. 55-70.

LÉONTIEV, A. Le développement du psychisme. 3. ed. Paris: Editions Sociales, 1976.

MAINGUENEAU, Dominique. Análise de textos de comunicação. São Paulo: Cortez, 2000.

MARX, Karl. Manuscritos econômico-filosóficos. Lisboa: Edições 70, 1993.

SCHAFF, Adam. Linguagem e conhecimento. Coimbra: Almedina, 1976.

SCHWARTZ, Yves. Travail et Philosophie. Convocations mutuelles. 2. ed. Toulouse: Octarès, 1994. . DURRIVE, Louis. Travail et ergologie. Entretiens sur l'activité humaine. Toulouse: Octares, 2003.

SOUZA E SILVA, Maria Cecília P.; FAÏTA, Daniel. Linguagem e trabalho. Construção de objetos de análise no Brasil e na França. São Paulo: Cortez, 2002.

VYGOTSKI, L.S. Pensamento e linguagem. 3.ed. São Paulo: Martins Fontes, 2005. 